\title{
Air pollution, methane super-emitters, and oil and gas wells in Northern California: the relationship with migraine headache prevalence and exacerbation
}

Holly Elser ${ }^{1}$, Rachel Morello-Frosch², Alice Jacobson ${ }^{3}$, Alice Pressman³, Marianthi-Anna Kioumourtzoglou 4 , Richard Reimer ${ }^{5}$ and Joan A. Casey ${ }^{4^{*}}$ (D)

\begin{abstract}
Background: Migraine-an episodic disorder characterized by severe headache that can lead to disability-affects over 1 billion people worldwide. Prior studies have found that short-term exposure to fine particulate matter $\left(P M_{2.5}\right)$, nitrogen dioxide $\left(\mathrm{NO}_{2}\right)$, and ozone increases risk of migraine-related emergency department (ED) visits. Our objective was to characterize the association between long-term exposure to sources of harmful emissions and common air pollutants with both migraine headache and, among patients with migraine, headache severity.

Methods: From the Sutter Health electronic health record database, we identified 89,575 prevalent migraine cases between 2014 and 2018 using a migraine probability algorithm (MPA) score and 270,564 frequency-matched controls. Sutter Health delivers care to 3.5 million patients annually in Northern California. Exposures included 2015 annual average block group-level $\mathrm{PM}_{2.5}$ and $\mathrm{NO}_{2}$ concentrations, inverse-distance weighted (IDW) methane emissions from 60 super-emitters located within $10 \mathrm{~km}$ of participant residence between 2016 and 2018, and IDW active oil and gas wells in 2015 within $10 \mathrm{~km}$ of each participant. We used logistic and negative binomial mixed models to evaluate the association between environmental exposures and (1) migraine case status; and (2) migraine severity (i.e., MPA score > 100, triptan prescriptions, neurology visits, urgent care migraine visits, and ED migraine visits per person-year). Models controlled for age, sex, race/ethnicity, Medicaid use, primary care visits, and block group-level population density and poverty.

(Continued on next page)
\end{abstract}

\footnotetext{
* Correspondence: jac2250@cumc.columbia.edu

${ }^{4}$ Department of Environmental Health Sciences, Mailman School of Public

Health, Columbia University, 722 W 168th St, Rm 1206, New York, NY

10032-3727, USA

Full list of author information is available at the end of the article
}

(c) The Author(s). 2021, corrected publication May 2021. Open Access This article is licensed under a Creative Commons Attribution 4.0 International License, which permits use, sharing, adaptation, distribution and reproduction in any medium or format, as long as you give appropriate credit to the original author(s) and the source, provide a link to the Creative Commons licence, and indicate if changes were made. The images or other third party material in this article are included in the article's Creative Commons licence, unless indicated otherwise in a credit line to the material. If material is not included in the article's Creative Commons licence and your intended use is not permitted by statutory regulation or exceeds the permitted use, you will need to obtain permission directly from the copyright holder. To view a copy of this licence, visit http://creativecommons.org/licenses/by/4.0/. The Creative Commons Public Domain Dedication waiver (http:// creativecommons.org/publicdomain/zero/1.0/) applies to the data made available in this article, unless otherwise stated in a credit line to the data. 


\begin{abstract}
(Continued from previous page)
Results: In adjusted analyses, for each 5 ppb increase in $\mathrm{NO}_{2}$, we observed 2\% increased odds of migraine case status (95\% Cl: 1.00, 1.05) and for each 100,000 kg/hour increase in IDW methane emissions, the odds of case status also increased $(\mathrm{OR}=1.04,95 \% \mathrm{Cl}: 1.00,1.08)$. We found no association between $\mathrm{PM}_{2.5}$ or oil and gas wells and migraine case status. $\mathrm{PM}_{2.5}$ was linearly associated with neurology visits, migraine-specific urgent care visits, and MPA score > 100, but not triptans or ED visits. $\mathrm{NO}_{2}$ was associated with migraine-specific urgent care and ED visits, but not other severity measures. We observed limited or null associations between continuous measures of methane emissions and proximity to oil and gas wells and migraine severity.
\end{abstract}

Conclusions: Our findings illustrate the potential role of long-term exposure to multiple ambient air pollutants for prevalent migraine and migraine severity.

Keywords: Electronic health records, Migraine, Methane, oil and gas fields, Nitrogen dioxide, Particulate matter, Environmental exposure

\section{Introduction}

Migraine is an episodic disorder characterized by severe headache often associated with nausea or sensitivity to light and sound. In 2016, the estimated global prevalence of migraine was $14.4 \%$ with over 1.04 billion individuals affected [1]. In the United States (U.S.), migraine is most common among individuals aged 30 to 39 and follows a social gradient wherein migraine is less common among wealthier individuals [2,3]. Migraine can lead to disability; in the U.S., estimated annual costs associated with migraine range from $\$ 13$ to 16.6 billion annually due to lost productivity, work and school absences, and shortterm disability [4-7].

Given the episodic nature of migraine headache, considerable attention has been paid to the study and identification of common triggers. Among the most frequently self-reported triggers of migraine are sleep disturbances and fatigue; stress or relief of stress; menstruation and pregnancy; smoking; and food and alcohol [8-12]. Factors such as noise, season, and weather variations have also been implicated as migraine triggers [8, 13-15]. Examples of common sources of environmental noise that may precipitate a migraine attack include traffic-related noise from roads, railways, aircrafts, and parking cars [16]. Individuals with migraine frequently attribute their headaches to weather variations, including changes in temperature and barometric pressure [11, 13, 17-19].

Research to date also implicates short-term exposure to a variety of air pollutants as triggers for migraine headache. Fine particulate matter $\left(\mathrm{PM}_{2.5}\right)$ is among the most frequently studied pollutants; increased levels of $\mathrm{PM}_{2.5}$ have been associated with more frequent migraine-specific emergency department (ED) visits in Canada, Taipei, and South Korea [20-24], although, a case-crossover study of 7054 patients in Boston reported no significant association with ED visits [25]. In a timeseries study of 1059 ED visits recorded at a Vancouver hospital, levels of sulfur dioxide $\left(\mathrm{SO}_{2}\right)$ were associated with ED visits for migraine [26]. Levels of ozone, carbon monoxide, nitrogen dioxide $\left(\mathrm{NO}_{2}\right)$, and coarse particles $\left(\mathrm{PM}_{10}\right)$ have also been linked with migraine-specific ED visits in case-crossover studies based on daily clinic data from 1000,000 patients from the National Health Insurance Program in Taiwan [23, 24]. A cross-sectional survey of 7785 primary care patients of the Geisinger Clinic in 2014 found that individuals exposed to the highest levels of unconventional natural gas development were more likely to have migraine headache [27]. Unconventional natural gas development can produce $\mathrm{PM}_{2.5}$, volatile organic compounds (VOCs), noise and light pollution, and stressful community changes that could trigger migraine [28].

To date, few studies have considered the implications of long-term exposure to common environmental pollutants-which may capture potential residential disparities in the burden of headache based on local average air quality-and no analyses have been conducted in the Western U.S. or on specific air pollution sources. Recently, the California Air Resources Board (CARB) conducted an air survey of methane super-emitters, point sources of methane emissions, including dairies, landfills, refineries, and oil and gas infrastructure [29]. These facilities emit a variety of co-pollutants such as $\mathrm{SO}_{2}$, hydrogen sulfide, $\mathrm{PM}_{2.5}$, and VOCs [30-32], and the new CARB data provide an opportunity to assess their implications for migraine. California is also a top-10 U.S. producer of crude oil, with over 200,000 oil and gas wells drilled in the state [33].

The present study leverages data from the Sutter Health electronic health record (EHR) database in Northern California and builds on prior research linking air pollutants and migraine headache. Our analyses include an expanded set of exposure measures, including long-term ambient $\mathrm{PM}_{2.5}$ and $\mathrm{NO}_{2}$ concentrations, methane emissions, and active oil and gas wells as measured at the beginning of the study period. We selected these exposures, particularly methane super-emitters and active oil and gas wells, because if linked to 
migraine, policies could reduce emissions at the source. Whereas past research has largely relied on migrainespecific ED visits as a crude proxy for severe headache, we incorporate additional measures of headache severity. We conducted a case-control study to ascertain whether migraine case status was associated with long-term exposure to any of the four environmental exposure measures as compared with controls. Next, we conducted a case-case analysis to ascertain whether environmental exposures were associated with more severe headache among individuals with established diagnosis of migraine. We hypothesized a priori that environmental exposures would be associated with both migraine case status and with disease severity.

\section{Methods}

We conducted a case-control study and case-case analysis to examine the relationship between migraine severity and exposures of interest. This approach was selected based on computational feasibility, and because disease-based sampling is efficient when multiple exposures are considered and when the outcome of interest is relatively rare [34]. Cases and controls were identified through the Sutter Health EHR database. Sutter Health is a large, mixed-payer, integrated healthcare system in Northern California that delivers comprehensive medical services through its network of 24 acute-care hospitals and more than 100 ambulatory clinics. Approximately 3.5 million patients receive care through Sutter each year at hospitals and clinics located in 22 counties; our study subjects resided in 27 urban and rural counties. Sutter's Epic EHR (Epic Systems Corporation, Verona, Wiscon$\sin$ ) is fully integrated across all hospital and ambulatory sites. Data for cases and controls were retrospectively extracted from the Sutter EHR for the study period between January 1, 2014 and December 31, 2018.

Patient demographic data from the EHR included sex (male, female), race/ethnicity (non-Hispanic Asian, Black, white, other, or Hispanic); and marital status (divorced, separated, widowed; married or partnered; single; other or unknown). We used date of birth to compute age in years at the start of follow-up. Health characteristics extracted from the EHR included whether the individual was a Medicaid beneficiary (yes, no); body mass index (BMI) category in $\mathrm{kg} / \mathrm{m}^{2}$ [less than 18.5 (underweight); 18.5-24.9 (normal); 25-29.9 (overweight); 3034.9 (obese class 1 ); $35-39.9$ (obese class 2); 40 or more (obese class 3)]; number of and reason for primary care, specialty care, urgent care, and emergency department visits. We assigned residential address for the study period (2014-2018) based on address of record in October 2019. Using assigned residential address, we linked block group-level percent living below the federal poverty threshold and population density (individuals per $\mathrm{km}^{2}$ ) using data from the 2014-2018 American Community Survey.

\section{Migraine case ascertainment and control selection}

Both cases and controls were selected from the study base of eligible patients over the age of 18 with at least one primary care encounter during the five-year study period (2014-2018) that resided in one of 27 counties in Northern California. We ascertained case status using the Migraine Probability Algorithm (MPA), a validated approach for identification of individuals diagnosed with migraine from EHR data [35]. Briefly, a numeric score that ranges from zero to 101 is calculated based on the following criteria: encounters (hospital inpatient, emergency room and outpatient) with a primary or secondary diagnostic code for migraine from the International Classification of Diseases, Ninth Revision (ICD-9 346.xx) or Tenth Revision (ICD-10 G43.xxx); an ICD-9 or ICD10 code for migraine in the patient's Significant Health Problem List (SHP); and filled prescriptions for migraine-specific abortive medications (i.e., triptans, ergotamines). An MPA score greater than 10 is consistent with diagnosis of migraine. We selected three controls for every case from the Sutter EHR database. Controls were frequency matched to cases based on age category (18-29; 30-44; 45-54; 55-64; 65 or older), sex, year of entry into Sutter primary care, and primary-care followup time (0-6 months, 7-24 months, > 24 months).

\section{Migraine severity}

Among cases (i.e., individuals with MPA $>10$ ), we defined the following count variables to capture migraine severity (1) all-cause neurology visits per year; (2) migraine-specific urgent care visits per year; (3) triptans prescribed per year. We additionally defined two dichotomous measures to capture migraine severity: (4) 0 versus $\geq 1$ migraine-specific emergency department (ED) visit during the study period; and (5) MPA score $>100$ (more severe) versus MPA score 11-100 (less severe).

\section{Air pollution, methane emission, and oil and gas wells}

We considered four separate exposure measures in our analyses. These included $\mathrm{PM}_{2.5}, \mathrm{NO}_{2}$, methane superemitters, and active oil and gas wells. Exposure to air pollutants and to oil and gas wells was estimated based on average values at the beginning of the study period (in 2015). Methane emissions measures were based on data collected between 2016 and 2018.

\section{$P M_{2.5}$ and $\mathrm{NO}_{2}$}

We used patient addresses to link annual average concentration of $\mathrm{PM}_{2.5}$ and $\mathrm{NO}_{2}$ estimates at the block group-level derived from annual-average integrated empirical geographic regression models [36]. The approach 
relied on universal kriging and took regulatory monitoring data, satellite imagery, and measures of land use and traffic as inputs. $\mathrm{PM}_{2.5}$ and $\mathrm{NO}_{2}$ achieved standardized RMSEs of $0.86 \mu \mathrm{g} / \mathrm{m}^{3}$ and $0.87 \mathrm{ppb}$, respectively. These variables were re-scaled such that coefficients in linear models correspond to each $5 \mu \mathrm{g} / \mathrm{m}^{3}$ increase in $\mathrm{PM}_{2.5}$ and each $5 \mathrm{ppb}$ increase in $\mathrm{NO}_{2}$, respectively.

\section{Methane emissions}

Data on methane emissions were provided by CARB as described in Duren et al. 2019 [29]. In brief, CARB led the first California Methane Survey to provide systematic information on methane point sources across the state via Next Generation Airborne Visible/Infrared Imaging Spectrometer (AVIRIS-NG) flights conducted between 2016 and 2018. The AVIRIS-NG flights identified 564 distinct sources of methane plumes and captured average hourly emission rates in kilograms per hour $(\mathrm{kg} /$ hour). Examples of sources of methane plumes identified by AVIRIS-NG flights included oil and gas wells, dairies, and landfills. To estimate exposure to methane emissions for the present study, we calculated the sum $\mathrm{kg} /$ hour of emitted methane from all sources within $10 \mathrm{~km}$ of each participant $j$ 's residence and weighted the emissions by the inverse-distance squared between each super-emitter, $i$, and patient $j$ 's residence:

$$
\sum_{i=1}^{n} \frac{E_{i}}{d_{i j}^{2}}
$$

where $E$ is the emission rate at super-emitter $i$ in $\mathrm{kg} /$ hour and $d$ is the distance in kilometers between superemitter $i$ and participant $j$. We created two exposure metrics based on methane emission rates. The first was the sum of methane emissions (in $\mathrm{kg} / \mathrm{hour}$ ) within 10 $\mathrm{km}$, re-scaled so that model coefficients corresponded to a $100,000 \mathrm{~kg} /$ hour increase in methane emissions. The second was an indicator variable for presence of any methane super-emitter within $10 \mathrm{~km}$.

\section{Oil and gas wells}

Finally, we obtained records for active oil and gas wells as of December 2015 from the California Division of Oil, Gas and Geothermal Resources website (CA DOGGR). To estimate exposure to active wells, we used inversedistance weighting (IDW) of active wells within $10 \mathrm{~km}$ of each participant, $j$ :

$$
\sum_{i=1}^{n} \frac{1}{d_{i j}^{2}}
$$

where $i$ is an active well located within $10 \mathrm{~km}$ of the participant and $d$ is the distance in kilometers between well $i$ and participant $j$. We created two exposure metrics based on exposure to active wells. The first was a continuous IDW sum of all active wells within $10 \mathrm{~km}$, re-scaled so that coefficients in linear models correspond to a 1000-unit increase in the IDW sum. The second was an indicator variable for presence of any active oil or gas well within $10 \mathrm{~km}$.

\section{Statistical analyses}

We first conducted a case-control analysis in which we examined the association between migraine status and each of the four exposures. Next, we conducted a casecase analysis to examine whether migraine severity was associated with each of the exposures.

\section{Case-control analysis}

For the case-control analyses, we used generalized linear mixed models with a logit link with county-specific random intercepts to account for potential within-county clustering. All models controlled for our matching variables: categorical age and sex, as recommended [37], and race/ethnicity, Medicaid use, number of primary care visits per year, and block group-level population density and poverty. We specified four separate statistical models to examine the association between migraine status and each of the environmental exposures of interest (i.e., $\mathrm{PM}_{2.5}, \mathrm{NO}_{2}$, methane super-emitters, and active oil and gas wells). We used generalized additive mixed models with penalized smoothing splines to capture potential non-linearities in the exposure-response relationships. As a secondary analysis, we used the binary exposure specification for both methane super-emitters and active wells (i.e., any super-emitter within $10 \mathrm{~km}$ vs. none and any well within $10 \mathrm{~km}$ vs. none).

\section{Case-case analysis}

In the case-case analyses, we utilized negative binomial mixed models (for count of neurology visits, migrainerelated urgent care visits, and prescriptions for triptans) and logistic mixed models (for $\geq 1$ migraine-related ED visit per person-year vs. less and MPA score $>100$ vs. 10-100) with random intercepts for county to examine the association between migraine severity and the exposure of interest. We controlled for the same set of potential confounding variables as described for the casecontrol analysis, assessed deviations from linearity using penalized smoothing splines, and as a secondary analysis considered binary specifications of super-emitters and active wells.

\section{Sensitivity analyses}

We conducted the following sensitivity analyses. First, we separated exposure to super-emitters into two categories: (1) dairy/cattle manure and landfills and (2) all other industrial types, which included power plants, refineries, wastewater treatment facilities, oil and gas 
distribution (e.g., oil/gas compressors, gas distribution lines), and oil and gas production (e.g., oil/gas waste lagoons, oil/gas plugged wells). We did so under the assumption that methane co-pollutant emissions would differ by these two categories. Second, we repeated our main case-control and case-case analyses with additional adjustment for BMI category and marital status. Finally, in our case-case analysis of migraine-specific ED visits, we additionally adjusted for distance from the patient's address of record to the nearest ED.

For all models, we evaluated residual spatial autocorrelation using Moran's I [38], which indicated no residual spatial autocorrelation in any of the analyses. Analyses were conducted using R 3.6.0 (R Foundation for Statistical Computing, Vienna, Austria). The Columbia University (Protcol \#: AAAT0085), University of California, Berkeley (Protocol \#: 2013-10-5693), and Sutter Health (IRBNet \#:1452543-1) Institutional Review Boards approved this study.

\section{Results}

The study based included 1,433,236 individuals with at least one primary care visit within the Sutter Health system in Northern California between 2014 and 2018. Based on MPA score, we initially identified $92,673 \mathrm{mi}-$ graine cases and 278,019 matched controls. We excluded 3065 cases and 7327 controls who resided outside of 27 Northern California counties; 29 cases and 100 controls who lacked block group-level poverty data; and 4 cases and 28 controls missing $\mathrm{PM}_{2.5}$ data (Supplementary Fig. 1). The final study population included 89,575 cases and 270,564 controls in 27 counties (Supplementary Fig. 2, Supplementary Fig. 3).

Migraine cases were most common between the ages of 30-44 years $(N=33,036,36.9 \%)$ and occurred predominantly among females $(N=73,908,82.5 \%)$. Migraine cases were more likely to be non-Hispanic white as compared with controls (58.7\% versus $48.2 \%$ ) and had more frequent primary care outpatient encounters and outpatient neurologist visits (Table 1). The 2015 average annual concentrations of $\mathrm{PM}_{2.5}$ and $\mathrm{NO}_{2} ;$ methane emission rates; and the location of active oil and gas wells are depicted in Fig. 1 . The median $\mathrm{PM}_{2.5}$ concentration at patient addresses was $8.7 \mu \mathrm{g} / \mathrm{m}^{3}(\mathrm{~min}=3.7$, $\max =13.3$ ) and the median $\mathrm{NO}_{2}$ concentration was 7.7 ppb $(\min =1.1, \max =15.2)$. Of 564 super-emitters surveyed in the state, $60(10.6 \%)$ were located within $10 \mathrm{~km}$ of study participants, including 35 dairies/landfills and 25 other types of super-emitters.

In our case-control analysis we observed only linear associations between exposure and migraine case status. We found some evidence for an association between migraine case status and block-group level $\mathrm{NO}_{2}$ concentration. We estimated that for every $5 \mathrm{ppb}$ increase in annual average $\mathrm{NO}_{2}$ concentration the odds of migraine case status increased by 1.02 times (95\% CI: 1.00, 1.05). We also estimated that for every $100,000 \mathrm{~kg} /$ hour increase in IDW sum of methane emissions within $10 \mathrm{~km}$, the odds of migraine case status also increased $(\mathrm{OR}=$ 1.04, 95\% CI: 1.00, 1.08). We found no evidence of an association between migraine case status and block-group level $\mathrm{PM}_{2.5}$ concentrations or for active oil or gas wells within $10 \mathrm{~km}$ (Fig. 2, Supplementary Table 1A). In our secondary analysis with dichotomized methane emission and active wells, we found no association between any super-emitter or any active well within $10 \mathrm{~km}$ and migraine (Supplementary Table 1B).

In our case-case analysis, meant to evaluate the association between environmental exposures and migraine frequency/severity, we observed mostly linear relationships, except for the association between $\mathrm{PM}_{2.5}$ and odds of any migraine ED visit during the study period (Supplementary Fig. 4). For the other severity outcomes, we found that each $5 \mu \mathrm{g} / \mathrm{m}^{3}$ increase in annual average block-group level $\mathrm{PM}_{2.5}$ concentration was associated with increased frequency of outpatient neurology visits $(R R=1.18,95 \% C I: 1.09,1.29)$, increased frequency of migraine-specific urgent care visits $(\mathrm{RR}=3.09,95 \% \mathrm{CI}$ : $2.28,4.18)$ and MPA score greater than $100(\mathrm{OR}=1.14$, $95 \%$ CI: $1.07,1.22$ ). We found no evidence of an association between increased $\mathrm{PM}_{2.5}$ concentration and frequency of prescribed triptans $(\mathrm{RR}=1.03,95 \% \mathrm{CI}$ : 0.97 , 1.10).

Increased block group-level $\mathrm{NO}_{2}$ concentration was not associated with triptans, outpatient neurology visits or MPA score, but we found that each $5 \mathrm{ppb}$ increase in $\mathrm{NO}_{2}$ concentration was associated with increased frequency of migraine-specific urgent care visits $(R R=1.22$, $95 \%$ CI: 1.02, 1.46) and with increased odds of having at least one migraine-specific ED visit during follow-up $(\mathrm{OR}=1.16$, 95\% CI: 1.05, 1.29) (Fig. 3, Supplementary Table 2A).

A 100,000-unit increase in the IDW sum of overall methane emissions within $10 \mathrm{~km}$ was associated with increased frequency of migraine-specific urgent care visits $(\mathrm{RR}=1.12,95 \% \mathrm{CI}: 0.92,1.36)$. Having any methane emitter within $10 \mathrm{~km}$ was also associated with increased frequency of urgent care visits ( $R R=1.32,95 \%$ CI: 1.14, 1.54) (Fig. 3, Supplementary Tables 2A and 2B). Proximity to super-emitters was not associated with the frequency of triptan prescriptions, outpatient neurologist visits, migraine-specific ED visits, or MPA score. Presence of any active oil and gas wells within $10 \mathrm{~km}$ was associated with increased frequency of outpatient neurologist visits $(\mathrm{RR}=$ $1.09,95 \%$ CI: 1.03, 1.16), frequency of migraine-specific urgent care visits ( $R R=1.43,95 \% \mathrm{CI}: 1.21,1.70)$, and odds of at least one migraine-specific ED encounter per personyear of follow-up $(\mathrm{OR}=1.11,95 \% \mathrm{CI}: 1.00,1.24)$. We 
Table 1 Patient demographics, healthcare utilization, and environmental exposures for migraine cases and controls from Sutter Health in Northern California, 2014-2018

\begin{tabular}{|c|c|c|}
\hline & $\begin{array}{l}\text { Migraine cases } \\
N=89,575\end{array}$ & $\begin{array}{l}\text { Controls }^{\mathrm{a}} \\
N=270,564\end{array}$ \\
\hline \multicolumn{3}{|l|}{ Patient Demographics } \\
\hline \multicolumn{3}{|l|}{ Age Category, N (\%) } \\
\hline 18-29 years & $16,952(18.9)$ & $51,112(18.9)$ \\
\hline 30-44 years & $33,036(36.9)$ & $99,792(36.9)$ \\
\hline $45-54$ years & $19,226(21.5)$ & $58,169(21.5)$ \\
\hline $55-64$ years & $12,578(14.0)$ & $38,093(14.1)$ \\
\hline$\geq 65$ years & $7783(8.7)$ & $23,399(8.7)$ \\
\hline \multicolumn{3}{|l|}{ Sex, N (\%) } \\
\hline Female & $73,908(82.5)$ & $223,230(82.5)$ \\
\hline Male & $15,667(17.5)$ & $47,334(17.5)$ \\
\hline \multicolumn{3}{|l|}{ Race/Ethnicity, N (\%) } \\
\hline \multicolumn{3}{|l|}{ Non-Hispanic } \\
\hline Asian & $9278(10.4)$ & $52,794(19.9)$ \\
\hline Black & $3685(4.1)$ & $10,253(3.8)$ \\
\hline White & $52,579(58.7)$ & $130,418(48.2)$ \\
\hline Other & $11,351(12.7)$ & $41,907(15.5)$ \\
\hline Hispanic & $12,682(14.2)$ & $34,192(12.6)$ \\
\hline \multicolumn{3}{|l|}{ Marital Status, N (\%) } \\
\hline Divorced/Separated/Widowed & $7444(8.3)$ & $18,881(7.0)$ \\
\hline Married/Significant Other & $51,390(57.4)$ & $155,644(57.5)$ \\
\hline Single & $22,659(25.3)$ & $63,801(23.6)$ \\
\hline Other/Unknown & $8082(9.0)$ & $32,238(11.9)$ \\
\hline \multicolumn{3}{|l|}{ Body Mass Index Category $\left(\mathbf{k g} / \mathbf{m}^{3}\right), \mathrm{N}(\%)$} \\
\hline Underweight $(<18.5)$ & $1672(1.9)$ & $5636(2.0)$ \\
\hline Normal (18.5-24.9) & $33,801(37.7)$ & $112,014(41.4)$ \\
\hline Overweight (25-29.9) & $26,969(30.1)$ & $79,209(29.3)$ \\
\hline Obese Class 1 (30-34.9) & $14,595(16.3)$ & $39,405(14.6)$ \\
\hline Obese Class 2 (35-39.9) & $6835(7.6)$ & $17,388(6.4)$ \\
\hline Obese Class 3 (40+) & $4614(5.2)$ & $11,658(4.3)$ \\
\hline Missing & $1089(1.2)$ & $5254(1.9)$ \\
\hline \multicolumn{3}{|l|}{ Block Group-Level Variables, Median (IQR) } \\
\hline Percent Poverty & $7.2(3.5,14.3)$ & $6.6(3.2,13.1)$ \\
\hline Population Density (individuals per $\mathrm{km}^{2}$ ) & $2211(901,3593)$ & $2292(954,3592)$ \\
\hline \multicolumn{3}{|l|}{ Medicaid Beneficiary, N (\%) } \\
\hline Yes & $6929(7.7)$ & $15,105(5.6)$ \\
\hline No & $82,646(92.3)$ & $255,459(94.4)$ \\
\hline \multicolumn{3}{|l|}{ Healthcare Utilization } \\
\hline \multicolumn{3}{|l|}{ Encounters per person-year } \\
\hline Primary care, Median (IQR) & $2.4(1.4,4.0)$ & $1.9(1.2,3.1)$ \\
\hline Neurology, Mean (SD) & $1.2(3.4)$ & $0.2(1.0)$ \\
\hline Urgent Care (Migraine-Specific), Mean (SD) & $0.2(2.7)$ & - \\
\hline Emergency (Migraine-Specific), N (\%) & $0.1(0.7)$ & - \\
\hline$\geq 1$ visit during the study period & 3987 (4.5) & - \\
\hline
\end{tabular}


Table 1 Patient demographics, healthcare utilization, and environmental exposures for migraine cases and controls from Sutter Health in Northern California, 2014-2018 (Continued)

\begin{tabular}{|c|c|c|}
\hline & $\begin{array}{l}\text { Migraine cases } \\
N=89,575\end{array}$ & $\begin{array}{l}\text { Controls }^{\mathrm{a}} \\
N=270,564\end{array}$ \\
\hline$<1$ visit during the study period & $85,588(95.5)$ & - \\
\hline Triptan prescriptions per person-year, mean (SD) & $0.6(2.6)$ & \\
\hline MPA Score - N (\%) & $66.6(31.5)$ & - \\
\hline $11-100$ & $59,599(66.5)$ & - \\
\hline$>100$ & $29,976(33.5)$ & - \\
\hline \multicolumn{3}{|l|}{ Environmental Exposures } \\
\hline \multicolumn{3}{|l|}{ Air Pollutants, Median (IQR) } \\
\hline $\mathrm{NO}_{2}, \mathrm{ppb}$ & $7.7(5.7,10.2)$ & $8.1(5.9,10.4)$ \\
\hline $\mathrm{PM}_{2.5}, \mu \mathrm{g} / \mathrm{m}^{3}$ & $8.7(7.8,9.6)$ & $8.9(7.8,9.7)$ \\
\hline \multicolumn{3}{|l|}{$\mathrm{CH}_{4}$ Emissions } \\
\hline Any super-emitter within 10 km, N (\%) & $18,457(20.6)$ & $57,224(21.1)$ \\
\hline Total IDW emissions in kg/hour, Mean (SD) & $21,461(192,973)$ & $26,070(180,548)$ \\
\hline \multicolumn{3}{|l|}{ Active Oil and Gas wells } \\
\hline Any oil or gas well within 10 km, N (\%) & $13,179(14.7)$ & $37,010(13.7)$ \\
\hline Total IDW wells, Mean (SD) & $604(6468)$ & $603(6459)$ \\
\hline
\end{tabular}

IDW Inverse-distance weighted; IQR Interquartile range; MPA Migraine probability algorithm ${ }^{\text {a }}$ Frequency-matched on age category, sex, year of entry into Sutter primary care, and primary-care follow-up time (0-6 months, 7-24 months, $\geq 24$ months)

found no evidence of an association between our continuous measure of active oil and gas wells and any of the five measures of migraine severity (Fig. 3, Supplementary Tables $2 \mathrm{~A}$ and $2 \mathrm{~B}$ ).

We conducted a sensitivity analysis in which we separately considered dairies and landfills versus all other methane super-emitters. Overall, these findings were largely consistent with our main findings for both the casecontrol and case-case analyses; the association was stronger for dairies and landfills $(\mathrm{RR}=1.18,95 \% \mathrm{CI}$ : $0.37,3.87)$ than for other super-emitters $(1.08,95 \% \mathrm{CI}$ : $0.85,1.36)$, albeit with widely overlapping confidence intervals. In re-analysis of the case-control and case-cases studies with additional controls for BMI category and marital status, results did not differ from those of our primary analysis (Supplementary Figs. 5 and 6). Results were also unchanged when we incorporated distance to the nearest Sutter hospital in the ED visit case-case analyses (Supplementary Fig. 7).

\section{Discussion}

Past research links short-term exposure to a range of air pollutants with ED visits migraine headache. Our study builds upon previous studies and considers the implications of long-term environmental exposures for migraine. Using data from the Sutter Health EHR database in Northern California, we examined relationships between a wide range of environmental exposures-including $\mathrm{PM}_{2.5}, \mathrm{NO}_{2}$, methane super-emitters, and oil and gas wells-and both migraine headache and headache severity among patients with migraine. Our case-control analysis revealed increased odds of exposure to $\mathrm{NO}_{2}$ and methane super-emitters among patients with migraine as compared with frequency-matched population controls without clinical diagnosis of migraine. In our casecase analysis, migraine severity-as measured by frequency of triptan prescriptions, outpatient neurology visits, migraine-specific urgent care and ED visits, and MPA score-was most strongly and consistently associated with average $\mathrm{PM}_{2.5}$ and $\mathrm{NO}_{2}$ exposure.

Research to date has focused primarily on short-term exposure to air pollutants as a trigger for migraine. Although relatively few studies have focused on chronic exposure, evidence to date nevertheless suggests that chronic exposure to common pollutants may be important in the etiology, severity, or frequency of headache including migraine. Using linked records from the Taiwan National Health Insurance Research Database and Taiwan Air Quality Monitoring Database, Hong et al. (2020) found that frequency of recurrent headaches among children younger than 18 years of age increased with higher-level exposure to several air pollutants including $\mathrm{PM}_{2.5}, \mathrm{CH}_{4}, \mathrm{NO}_{2}$, and total hydrocarbons [39]. Adetona et al. (2020) conducted a cross-sectional study among residents of a community adjacent to a large open landfill in Lagos, Nigeria. Results of that study indicated that chronic exposure to emissions from open combustion of municipal solid waste-a major source of particulate matter, polycyclic aromatic hydrocarbons, and toxicants such as polychlorinated biphenyls and 


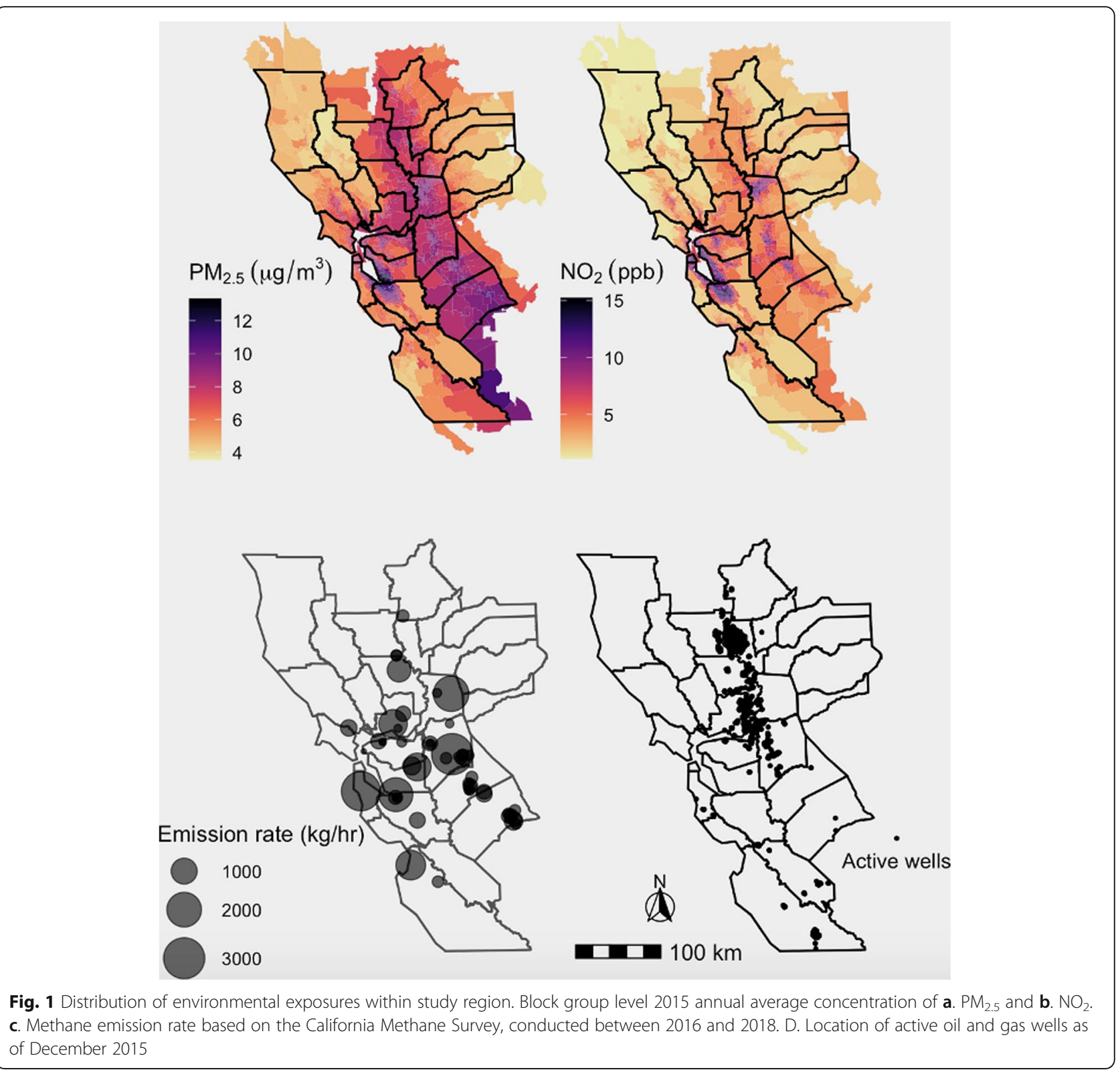

brominated flame retardants-was associated with increased odds of daily occurrence of headache [40]. Moreover, in animal models, chronic exposure to acrolein, which is prevalent in both indoor and outdoor air pollution, yielded physiologic changes consistent with migraine $[41,42]$.

Results of the present study further demonstrate the potential importance of long-term residential exposures for migraine severity. One important implication of these findings is that in more heavily polluted communities, individuals may be more likely to suffer from migraines or may suffer from more frequent headaches. The existing literature consistently demonstrates the disproportionate burden of air pollution in already disadvantaged communities [43-45], and the substantial economic and social costs associated with migraine in the United States [2, 46-49]. Our findings therefore motivate careful examination of the extent to which disparate levels of exposure to harmful emissions and levels of community air pollution translate to greater burden of migraine headache and the associated economic and social costs particularly in already disadvantaged communities.

To our knowledge, ours is the first study to examine the implications of exposure to methane super-emitters for migraine; we identified an association between super-emitter exposure and migraine case status but not migraine severity. Methane super-emitters included 


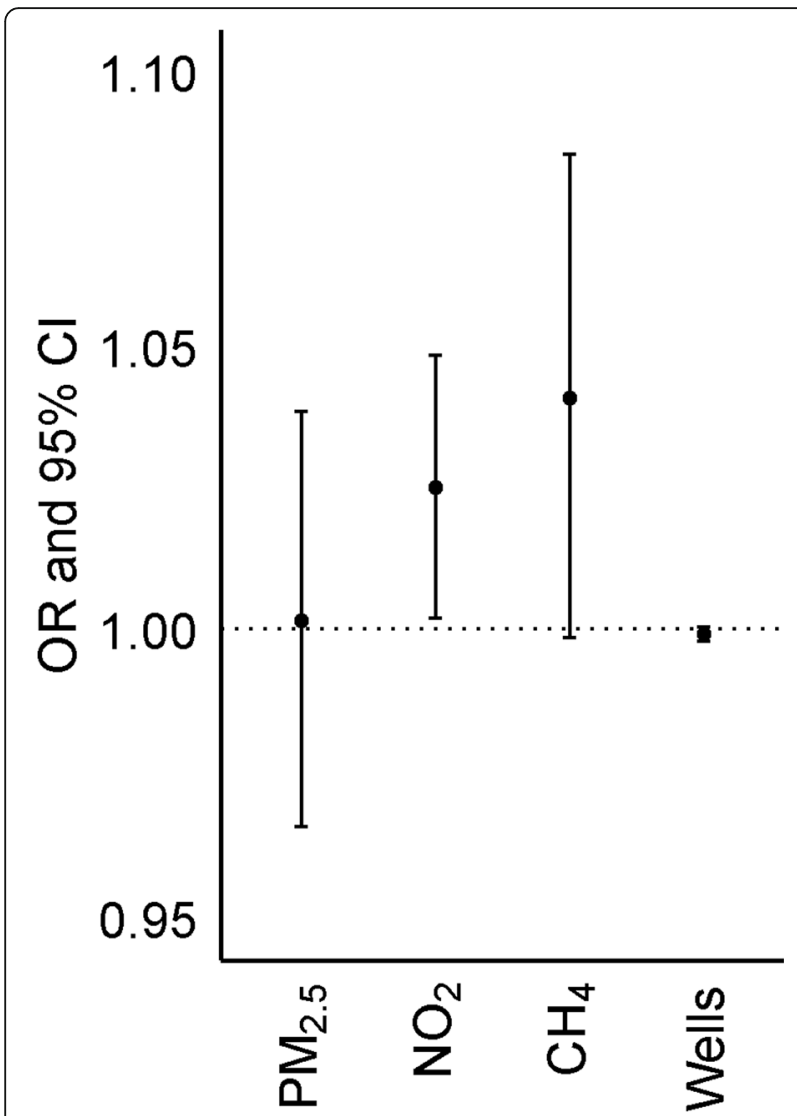

Fig. 2 Association between environmental exposures and odds of being a migraine case versus control. Results from a mixed logistic model with a random intercept for county adjusted for individuallevel age category (18-29, 30-44, 45-54, 55-64, $\geq 65)$, race/ethnicity (Hispanic, non-Hispanic Asian, non-Hispanic-Black, non-Hispanic White, and non-Hispanic other), sex, Medicaid use, number of primary care visits per person-year during the study period, and block group-level population density and poverty. OR are per $5 \mu \mathrm{g} /$ $\mathrm{m}^{3}$ for $\mathrm{PM}_{2.5}$, per $5 \mathrm{ppb}$ for $\mathrm{NO}_{2}$, per 100,000 kg/hour increase in IDW sum of methane emissions within $10 \mathrm{~km}$ for super-emitters, and per 1000-unit increase in IDW sum of all wells within $10 \mathrm{~km}$ for active oil and gas wells

dairies and waste lagoons, landfills, power plants, refineries, wastewater treatment facilities, and oil and gas production and distribution infrastructure. Although methane itself is not directly toxic to humans, it is often co-emitted with other noxious compounds. The heterogeneous group of super-emitters considered in this study also produce a wide range of co-pollutants including volatile organic compounds, ammonia, hydrogen sulfide, and particulate matter, several of which are odorous [50-52]. Methane also contributes to the formation of ground-level ozone, previously implicated as a trigger for migraine headache [23, 24]. In addition, super-emitters, such as oil and gas wells, produce noise pollution [53]. Both noise and odors have been consistently linked with migraine headache $[8,13-15]$.
Importantly, we assigned methane super-emitter exposure based on data collected between 2016 and 2018, while we included migraine cases in the Sutter EHR database between 2014 and 2018. This complicates the temporal ordering of exposure and response. However, reverse causality seems an implausible alternative explanation for our results, as we know of no reason that individuals with migraine would cause systematic increases in local super-emitter exposure or would move closer to a super-emitter post-diagnosis. It is possible, however, that our findings reflect residential sorting of individuals predisposed to migraine into localities where methane emissions are higher on average $[54,55]$. In the U.S., migraine follows a social gradient and is more common among lower-income individuals who are also more likely to live in more polluted neighborhoods $[2,3]$. We aimed to address this important source of confounding by adjusting for patient Medicaid use and block-grouplevel population density and poverty. Future research should specifically examine co-pollutants that may explain the apparent link between methane emissions and migraine, and to disentangle the role of residential sorting and confounding by socioeconomic status from any etiologic role that methane plays in the onset or exacerbation of migraine headaches.

Unlike several prior studies that rely on ED visits as a rough proxy for disease severity, our case-case analysis considered a more comprehensive set of proxies obtained from EHR data including non-emergency migraine-specific healthcare visits, migraine-related medication use, a validated migraine severity score, and overall neurology visits among patients with migraine. We also used splines to consider potential nonlinearities in exposure-response relationships between each environmental exposure and our migraine severity outcome measures. Consistent with past research [2, 3], we observed an association between $\mathrm{NO}_{2}$ exposure and migraine severity as measured by migraine-specific urgent care visits and migraine-specific ED visits even at $\mathrm{NO}_{2}$ levels well below the current national standards (our population-average annual exposure was around 8 ppb compared to the U.S. Environmental Protection Agency annual standard of $53 \mathrm{ppb}$ ).

Past research finds an association between short-term exposure to $\mathrm{PM}_{2.5}$ and migraine-specific $\mathrm{ED}$ visits $[2,3]$. Our analysis demonstrated an association with longterm, annual average $\mathrm{PM}_{2.5}$ across a more comprehensive set of clinical proxies for headache severity, including outpatient neurology visits and migraine-specific urgent care visits. For ED visits, we found a paradoxical inverse $\mathrm{u}$-shaped exposure-response wherein individuals with the lowest and highest levels of average $\mathrm{PM}_{2.5}$ had the lowest odds of ED visit. This relationship persisted even after we incorporated additional statistical controls 


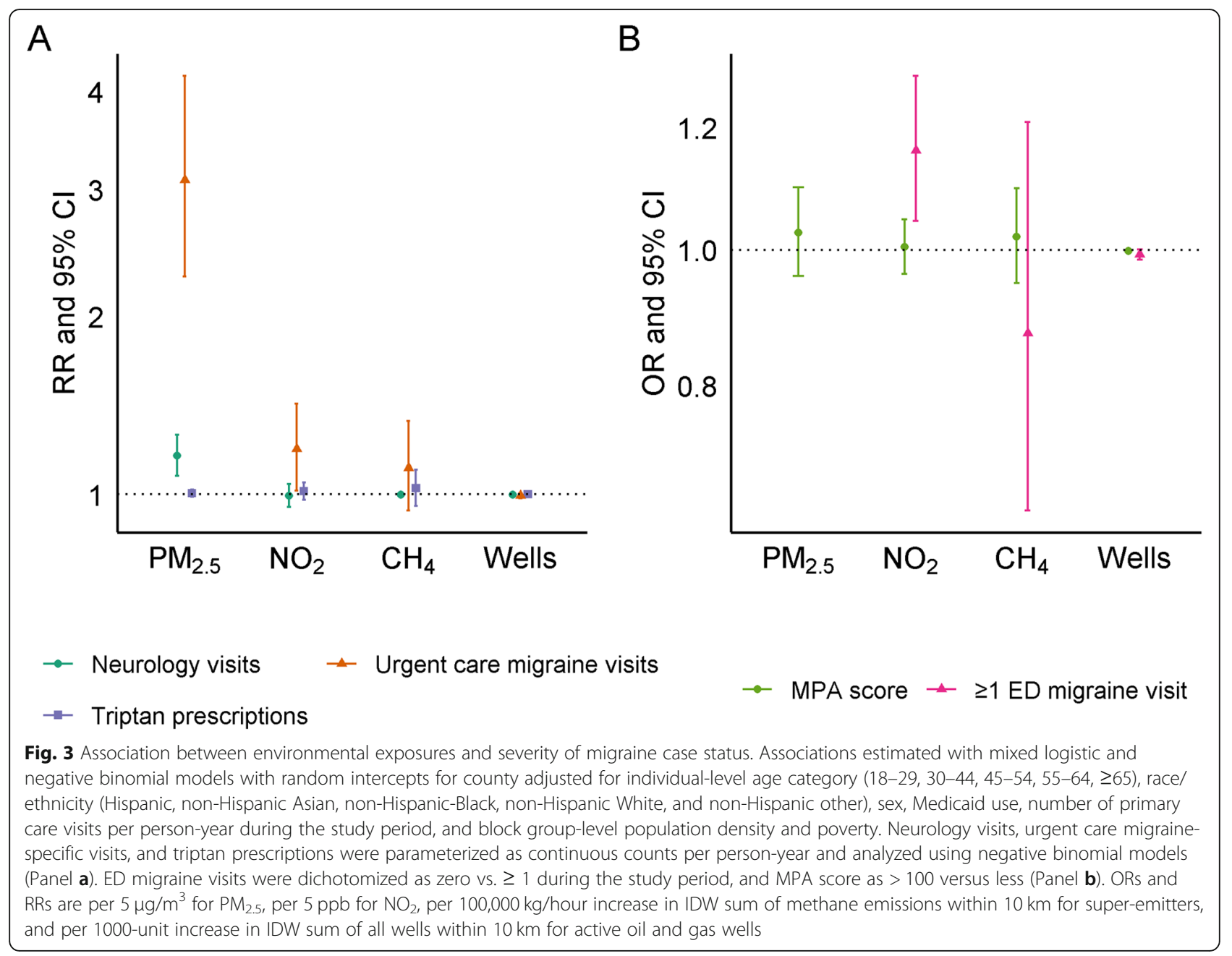

for distance to nearest Sutter ED. As our analysis differs from previous studies that consider short-term $\mathrm{PM}_{2.5}$ levels and risk of ED visits, this finding could reflect misalignment of the examined exposure window (annual average $\mathrm{PM}_{2.5}$ ) with an acute outcome (ED visits).

Communities with higher annual $\mathrm{PM}_{2.5}$ concentrations may also have higher peak and long-term average exposure that gives rise to ED visits. We know of no research that demonstrates higher levels of $\mathrm{PM}_{2.5}$ as protective against migraine headaches. This relationship could reflect residential sorting where individuals with migraine move out of high $\mathrm{PM}_{2.5}$ communities. As migrainespecific emergency department visits are relatively rare in these data, we suspect that the observed relationship is driven by relatively less frequent use of emergency departments for headache among individuals living in the few counties with the highest $\mathrm{PM}_{2.5}$ levels. This finding also implies possible geographic disparities in either access to or use of care for severe migraine headaches unrelated to proximity or insurance status that should be explored in future research.
The association between $\mathrm{PM}_{2.5}$ and migraine severity may be partly explained by correlation between $\mathrm{PM}_{2.5}$ and other exposures known to precipitate migraine headache (namely, noise and noxious odors) [8, 13-15]. $\mathrm{PM}_{2.5}$, is known to activate the sympathetic nervous system, result in systemic inflammation, and trigger cardiovascular events $[56,57]$, and may also directly result in migraine. The smallest fraction of the $\mathrm{PM}_{2.5}$ particles, ultrafine particulate matter $(\leq 0.1 \mu \mathrm{m}$ in diameter [58]), may have a disproportionately large role. Ultrafine particles-unlike the larger component particles of $\mathrm{PM}_{2.5}$-can transverse the blood-brain barrier and reach the brain directly through the olfactory bulb [59].

Despite making up just a small portion of the total $\mathrm{PM}_{2.5}$ mass concentration, these circumstances raise the possibility that the apparent association between $\mathrm{PM}_{2.5}$ and migraine severity in this and previous studies could be partially explained by neurotoxic effects secondary to exposure to the ultrafine component of $\mathrm{PM}_{2.5}[60,61]$. The U.S. EPA does not regulate ultrafine particulate matter, meaning exposure estimates are sparse and 
epidemiologic studies rare. Future migraine research should aim to evaluate the effects of ultrafine particles on migraine and disentangle the effects of concomitant exposure to noise, odor, $\mathrm{PM}_{2.5}$, and ultrafine particles.

Our analyses include all individuals with migraine followed from 2014 to 2018 but do not distinguish between individuals with previously diagnosed migraine at the beginning of the study period (i.e., prevalent cases) and individuals diagnosed with migraine throughout the study period (i.e., incident cases). This makes ascertainment of an etiologic role of environmental exposures in either migraine onset or exacerbation challenging. As discussed previously, we cannot eliminate the possibility that our findings may reflect residential sorting, wherein individuals with existing migraine are more likely to reside in health-harming communities, for example those of lower socioeconomic status or with higher levels of pollutants. Alternatively, individuals with migraine and the financial means to do so may choose to leave communities with environmental exposures that trigger their headaches. The direction and magnitude of bias attributable to residential sorting is therefore difficult to anticipate.

Although our analyses include individuals with migraine followed from 2014 to 2018, exposures were either measured at the beginning of the study period in 2015 (annual average $\mathrm{PM}_{2.5}, \mathrm{NO}_{2}$, and presence of oil and gas wells) or as values between 2016 and 2018 (methane super-emitter emissions and presence). We assume relatively stable levels of long-term air pollution and oil and gas well exposure during the study period. Methane super-emitter measurements took place between 2016 and 2018, but emission trends likely vary over time. Exposures were also assigned based on a single residential address on the index date and therefore do not capture exposure accrued during time spent outside the home and also do not reflect potential moves between 2014 and 2018. Future research should endeavor to incorporate time-varying measures of air pollution, oil and gas wells, and methane emissions in relation to migraine onset and exacerbation in order to better characterize the dynamic relationship between environment and migraine.

Residential addresses were ascertained in October 2019 after the study period. Selection bias could result, for example, if individuals with migraine headache in highly polluted counties moved to less polluted counties outside of the Sutter catchment areas. Because a small minority of individuals lived outside of the Sutter catchment area in October 2019 (3.3\% of cases and 2.6\% of controls), we expect any resultant bias to be minimal. Some differential exposure misclassification could also arise if individuals with migraine headache in highly polluted counties moved to less polluted counties within the Sutter catchment area, leading to systematic underestimation of long-term exposures among cases, and therefore, underestimation of effect estimates.

While our study incorporates a more comprehensive set of proxy measures for migraine headaches as compared with previous studies (which typically relied on migraine ED visits), we lacked any direct measure of headache frequency among patients with migraine (e.g., headache diaries). Our results rest on patients seeking clinical care for migraine. If individuals with higher levels of environmental exposure were systematically less likely to seek migraine treatment, our results may be attenuated. Headache diaries would circumvent this problem and further examination of the relationship between migraine and the environment in datasets where direct measures of headache frequency are available [62-64] would further our understanding of this relationship.

Fourth, our analysis includes a comprehensive set of potential confounding variables. Nevertheless, we note the absence of several critical variables-including individual-level income, educational attainment, and employment status-that may be important confounders in studies that use treatment seeking as a proxy for headache severity, given past research showing that migraine plays a key role in disability, absence from work or school, and that migraine follows a social gradient and is less common in wealthier individuals [2, 5, 7]. Further, we lacked information on environmental noise pollution, which may trigger migraines [65] and often co-occurs with sources of air pollution.

Finally, we drew participants from a single healthcare system in Northern California. This may limit generalizability to other populations including individuals who are uninsured or have limited health insurance. Northern California also differs meaningfully from the rest of the U.S. in the quality and extent of environmental exposures and population demographics. The relationship between migraine and environment may differ by region, season, and based on individual characteristics. This motivates ongoing study of the relationship between migraine in the environment in varied contexts.

\section{Conclusions}

In this study, we demonstrate an association between long-term $\mathrm{NO}_{2}$ and methane super-emitter exposure and odds of being a migraine patient. We also find annual average $\mathrm{NO}_{2}$ and $\mathrm{PM}_{2.5}$ exposure associated with migraine headache severity. Our study expanded the scope of environmental pollutants considered as risk factors for migraine and included numerous measures of migraine severity derived from EHR data and contributes to the existing literature on migraine and the environment by explicitly considering long-term exposure to common pollutants. These findings illustrate the 
potential role of ambient air pollution for prevalent migraine and migraine severity. Future studies are needed that establish the temporal ordering of exposure and outcome and the relevant exposure period as well as that determine the most relevant air pollutants. In addition, researchers should consider the potential heterogeneity in the relationship between migraine and the environment across different geographic contexts and within population subgroups. Such studies could identify environmental risk factors on which we could intervene to reduce the population burden of migraine.

\section{Abbreviations}

BMI: Body mass index; CARB: California air resources board; ED: Emergency department; EHR: Electronic health records; IDW: Inverse distance weighted; MPA: Migraine probability algorithm; $\mathrm{NO}_{2}$ : Nitrogen dioxide; $\mathrm{PM}_{2.5}$ : Fine particulate matter; $\mathrm{SO}_{2}$ : Sulfur dioxide; U.S.: United States; VOCs: Volatile organic compounds

\section{Supplementary Information}

The online version contains supplementary material available at https://doi. org/10.1186/s12940-021-00727-w.

\begin{abstract}
Additional file 1: Fig. S1. Ascertainment of migraine cases and controls from Sutter Health electronic health record data, 2015-2018. Fig. S2. Counties included in the analysis in Northern California (left) and distribution of Sutter hospitals (right). Fig. S3. Distribution of migraine cases and controls. Fig. S4. Flexible dose-response between levels of $\mathrm{PM}_{2.5}(\mu \mathrm{g} / \mathrm{m} 3)$ and odds of having $\geq 1$ ED visit over the course of the study period. From mixed logistic models with penalized smoothing splines for PM2.5, random intercept for county, adjusted for individuallevel age category $\left(18-29,30-44,45-54,55-64,{ }^{3} 65\right)$, race/ethnicity (Hispanic, non-Hispanic Asian, non-Hispanic-Black, non-Hispanic White, and non-Hispanic other), sex, Medicaid use, number of primary care visits per person-year during the study period, and block group-level population density and poverty. Fig. S5. Association between environmental exposures and odds of being a migraine case versus control. Fig. S6. Association between environmental exposures and severity of migraine case status. Fig. S7. Association between PM2.5 and migraine-specific ED visits, adjusted for distance to nearest Sutter hospital. Table S1A. Associations between continuous environmental exposures and migraine status. Table S1B. Associations between dichotomized environmental exposures and migraine status. Table S2A. Associations between continuous environmental exposures and measures of migraine severity. Table S2B. Associations between binary environmental exposures and measures of migraine severity.
\end{abstract}

\section{Acknowledgements}

The authors thank Kathy V. Tran, graduate of the School of Public Health at UC Berkeley, for her work in assembling the oil and gas well dataset and Sylvia Sudat, biostatistician at Sutter Health, for her assistance with patient geocoding and assembly of the analytic dataset.

\section{Authors' contributions}

JAC and RMF conceived the study. AP, HE, JAC, MAK, and RMF developed the study design and statistical methodology. AJ assembled the health data. JAC analyzed the data and produced the Figs. HE and JAC drafted the manuscript. All authors read, provided feedback, and approved the final manuscript.

\section{Funding}

This study was funded by the California Air Resources Board (CARB\#18RD018) and the National Institutes of Environmental Health Sciences (R00 ES027023 and P30 ES009089).

\section{Availability of data and materials}

The Sutter Health electronic health record data are considered Protected Health Information under the Health Insurance Portability and Accountability Act of 1996 (HIPAA) in the United States, and as such are not publiclyavailable. $\mathrm{PM}_{2.5}$ and $\mathrm{NO}_{2}$ data are available for download at: https://www. caces.us/data. Methane data are available via https:/www.nature.com/ articles/s41586-019-1720-3\#data-availability. Oil and gas well data are available at https://www.conservation.ca.gov/calgem/Pages/Oil-and-Gas.aspx.

\section{Declarations}

Ethics approval and consent to participate

The Columbia University (Protocol \#: AAAT0085),

University of California, Berkeley (Protocol \#: 2013-10-5693), and Sutter Health

(IRBNet \#: 1452543-1) Institutional Review Boards approved this study.

\section{Consent for publication}

Not applicable. Only anonymized data were used.

\section{Competing interests}

The authors declare that they have no conflicts of interest.

\section{Author details}

${ }^{1}$ Stanford University School of Medicine, Stanford Center for Population Health Sciences, Stanford, USA. ${ }^{2}$ Department of Environmental Science, Policy, and Management and School of Public Health, University of California Berkeley, Berkeley, CA, USA. ${ }^{3}$ Research, Development and Dissemination, Sutter Health, Sacramento, USA. ${ }^{4}$ Department of Environmental Health Sciences, Mailman School of Public Health, Columbia University, 722 W 168th St, Rm 1206, New York, NY 10032-3727, USA. ${ }^{5}$ Department of Neurology and Neurological Science, Stanford University School of Medicine, Stanford, USA.

Received: 19 August 2020 Accepted: 12 April 2021

Published online: 17 April 2021

\section{References}

1. Stovner LJ, Nichols E, Steiner TJ, Abd-Allah F, Abdelalim A, Al-Raddadi RM, et al. Global, regional, and national burden of migraine and tension-type headache, 1990-2016: a systematic analysis for the global burden of disease study 2016. Lancet Neurol. 2018;17(11):954-76. https://doi.org/10.1016/S14 74-4422(18)30322-3.

2. Lipton RB, Bigal ME, Diamond M, Freitag F, Reed M, Stewart WF. Migraine prevalence, disease burden, and the need for preventive therapy. Neurology. 2007;68(5):343-9. https://doi.org/10.1212/01.wnl.0000252808. 97649.21.

3. Lipton RB, Stewart WF, Diamond S, Diamond ML, Reed M. Prevalence and burden of migraine in the United States: data from the American migraine study II. Headache J Head Face Pain. 2001;41(7):646-57. https://doi.org/10.1 046/j.1526-4610.2001.041007646.x.

4. Lofland J. Impact of migraine headache in the United States. Adv Stud Pharm. 2007:4:8-10.

5. Porter JK, Di Tanna GL, Lipton RB, Sapra S, Villa G. Costs of acute headache medication use and productivity losses among patients with migraine: insights from three randomized controlled trials. PharmacoEconomics-open. 2019;3(3):411-7. https://doi.org/10.1007/s41669-018-0105-0.

6. Berg J, Ramadan NM. Societal burden of the headache. The headaches. Philadelphia: Lipencott \& Williams; 2006;35-42.

7. Gilligan AM, Foster SA, Sainski-Nguyen A, Sedgley R, Smith D, Morrow P. Direct and indirect costs among United States commercially insured employees with migraine. J Occup Environ Med. 2018;60(12):1120-7. https://doi.org/10.1097/JOM.0000000000001450.

8. Prince PB, Rapoport AM, Sheftell FD, Tepper SJ, Bigal ME. The effect of weather on headache. Headache J Head Face Pain. 2004;44(6):596-602. https://doi.org/10.1111/j.1526-4610.2004.446008.x.

9. Chabriat H, Danchot J, Michel P, Joire J, Henry P. Precipitating factors of headache. A prospective study in a national control-matched survey in 
migraineurs and nonmigraineurs. Headache J Head Face Pain. 1999;39(5): 335-8. https://doi.org/10.1046/j.1526-4610.1999.3905335.x.

10. Henry P, Auray J, Gaudin A, Dartigues J, Duru G. Lantéri-Minet M, et al. prevalence and clinical characteristics of migraine in France. Neurology. 2002;59(2):232-7. https://doi.org/10.1212/WNL.59.2.232.

11. Spierings EL, Ranke AH, Honkoop PC. Precipitating and aggravating factors of migraine versus tension-type headache. Headache J Head Face Pain. 2001;41(6):554-8.

12. Peatfield R, Glover V, Littlewood J, Sandler M, Clifford RF. The prevalence of diet-induced migraine. Cephalalgia. 1984;4(3):179-83. https://doi.org/10.104 6/j.1468-2982.1984.0403179.x

13. Wöber C, Holzhammer J, Zeitlhofer J, Wessely P, Wöber-Bingöl Ç. Trigger factors of migraine and tension-type headache: experience and knowledge of the patients. J Headache Pain. 2006;7(4):188-95. https://doi.org/10.1007/ s10194-006-0305-3.

14. Charles A. The evolution of a migraine attack-a review of recent evidence. Headache J Head Face Pain. 2013;53(2):413-9. https://doi.org/10.1111/hea d.12026.

15. Eross $E$, Dodick D, Eross M. The sinus, allergy and migraine study (SAMS) CME. Headache J Head Face Pain. 2007;47(2):213-24. https://doi.org/1 0.1111/j.1526-4610.2006.00688.x.

16. Friedman DI, De Ver Dye T. Migraine and the environment. Headache J Head Face Pain. 2009;49(6):941-52. https://doi.org/10.1111/j.1526-4610.2009. 01443.x.

17. Yang AC, Fuh J-L, Huang NE, Shia B-C, Peng C-K, Wang S-J. Temporal associations between weather and headache: analysis by empirical mode decomposition. PLoS One. 2011;6(1):e14612. https://doi.org/10.1371/journal. pone.0014612.

18. Turner L, Molgaard C, Gardner C, Rothrock J, Stang P. Migraine trigger factors in a non-clinical Mexican-American population in San Diego county: implications for etiology. Cephalalgia. 1995;15(6):523-30. https://doi.org/10.1 046/j.1468-2982.1995.1506523.x.

19. von Mackensen S, Hoeppe P, Maarouf A, Tourigny P, Nowak D. Prevalence of weather sensitivity in Germany and Canada. Int J Biometeorol. 2005;49(3): 156-66. https://doi.org/10.1007/s00484-004-0226-2.

20. Szyszkowicz M, Kaplan G, Grafstein E, Rowe B. Emergency department visits for migraine and headache: a multi-city study. Int J Occup Med Environ Health. 2009;22(3):235-42.

21. Szyszkowicz M, Stieb DM, Rowe BH. Air pollution and daily ED visits for migraine and headache in Edmonton, Canada. Am J Emerg Med. 2009;27(4): 391-6. https://doi.org/10.1016/j.ajem.2008.03.013.

22. Lee H, Myung W, Cheong H-K, Yi S-M, Hong Y-C, Cho S-I, et al. Ambient air pollution exposure and risk of migraine: synergistic effect with high temperature. Environ Int. 2018;121(Pt 1):383-91. https://doi.org/10.1016/j. envint.2018.09.022.

23. Chen C-C, Tsai S-S, Yang C-Y. Association between fine particulate air pollution and daily clinic visits for migraine in a subtropical city: Taipei, Taiwan. Int J Environ Res Public Health. 2015;12(5):4697-708. https://doi. org/10.3390/ijerph120504697.

24. Chiu H-F, Yang C-Y. Air pollution and daily clinic visits for migraine in a subtropical city: Taipei, Taiwan. J Toxic Environ Health A. 2015;78(9):549-58. https://doi.org/10.1080/15287394.2015.983218.

25. Mukamal KJ, Wellenius GA, Suh HH, Mittleman MA. Weather and air pollution as triggers of severe headaches. Neurology. 2009;72(10):922-7. https://doi.org/10.1212/01.wnl.0000344152.56020.94.

26. Szyszkowicz M, Rowe B, Kaplan G. Ambient Sulphur dioxide exposure and emergency department visits for migraine in Vancouver, Canada. Int J Occup Med Environ Health. 2009;22(1):7-12. https://doi.org/10.2478/v10001-009-0006-7.

27. Tustin AW, Hirsch AG, Rasmussen SG, Casey JA, Bandeen-Roche K, Schwartz BS. Associations between unconventional natural gas development and nasal and sinus, migraine headache, and fatigue symptoms in Pennsylvania. Environ Health Perspect. 2017;125(2):189-97. https://doi.org/10.1289/EHP281.

28. Adgate JL, Goldstein BD, McKenzie LM. Potential public health hazards, exposures and health effects from unconventional natural gas development. Environ Sci Technol. 2014;48(15):8307-20. https://doi.org/10.1021/es404621d.

29. Duren RM, Thorpe AK, Foster KT, Rafiq T, Hopkins FM, Yadav V, et al. California's methane super-emitters. Nature. 2019;575(7781):180-4. https:// doi.org/10.1038/s41586-019-1720-3.

30. Zavala-Araiza D, Alvarez RA, Lyon DR, Allen DT, Marchese AJ, Zimmerle DJ, et al. Super-emitters in natural gas infrastructure are caused by abnormal process conditions. Nat Commun. 2017:8(1):1-10.
31. California Air Resources Board. Landfill Activities 2020 [Available from: https://ww2.arb.ca.gov/sites/default/files/classic/cc/landfills/landfills.htm.

32. California Air Resources Board. Refiner Emergency Air Monitoring Assessment Report Objective 2: Evaluation of Air Monitoring Capabilities, Gaps, and Potential Enhancements 2019 [Available from: https://ww3.arb.ca. gov/fuels/carefinery/crseam/o2reamarfinal.pdf?_ga $=2.149873781 .2$ 58059090.1593094388-358911420.1591295298.

33. Energy Information Agency. California State Energy Profile 2020 [Available from: https://www.eia.gov/state/print.php?sid=CA.

34. Jewell NP. Statistics for epidemiology. Boca Raton: CRC press; 2003. https:// doi.org/10.1201/9781482286014.

35. Pressman A, Jacobson A, Eguilos R, Gelfand A, Huynh C, Hamilton L, et al. Prevalence of migraine in a diverse community - electronic methods for migraine ascertainment in a large integrated health plan. Cephalalgia. 2016; 36(4):325-34. https://doi.org/10.1177/0333102415590242.

36. Kim SY, Bechle M, Hankey S, Sheppard L, Szpiro AA, Marshall JD. Concentrations of criteria pollutants in the contiguous U.S., 1979-2015: Role of prediction model parsimony in integrated empirical geographic regression. PLoS One. 2020;15(2):e0228535.

37. Mansournia MA, Jewell NP, Greenland S. Case-control matching: effects, misconceptions, and recommendations. Eur J Epidemiol. 2018;33(1):5-14. https://doi.org/10.1007/s10654-017-0325-0.

38. Bivand RS, Pebesma EJ, Gomez-Rubio V. In: Gentleman R, Hornik K, Parmigiani G, editors. Applied spatial data analysis with R. New York, NY: Springer; 2008.

39. Hong S-Y, Wan L, Lin H-J, Lin C-L, Wei C-C. Long-term ambient air pollutant exposure and risk of recurrent headache in children: a 12-year cohort study. Int J Environ Res Public Health. 2020;17(23):9140. https://doi.org/10.3390/ ijerph17239140.

40. Adetona O, Ozoh OB, Oluseyi T, Uzoegwu Q, Odei J, Lucas M. An exploratory evaluation of the potential pulmonary, neurological and other health effects of chronic exposure to emissions from municipal solid waste fires at a large dumpsite in Olusosun, Lagos, Nigeria. Environ Sci Pollut Res. 2020;27(24):30885-92. https://doi.org/10.1007/s11356-020-09701-4.

41. Kunkler PE, Zhang L, Johnson PL, Oxford GS, Hurley JH. Induction of chronic migraine phenotypes in a rat model after environmental irritant exposure. Pain. 2018;159(3):540-9. https://doi.org/10.1097/j.pain.0000000000001124.

42. Kunkler PE, Zhang L, Pellman JJ, Oxford GS, Hurley JH. Sensitization of the trigeminovascular system following environmental irritant exposure. Cephalalgia. 2015;35(13):1192-201. https://doi.org/10.1177/033310241557484 5.

43. Woo B, Kravitz-Wirtz N, Sass V, Crowder K, Teixeira S, Takeuchi DT. Residential segregation and racial/ethnic disparities in ambient air pollution. Race Soc Probl. 2019;11(1):60-7. https://doi.org/10.1007/s12552-018-9254-0.

44. Colmer J, Hardman I, Shimshack J, Voorheis J. Disparities in PM2. 5 air pollution in the United States. Science. 2020;369(6503):575-8. https://doi. org/10.1126/science.aaz9353.

45. O'Neill MS, Jerrett M, Kawachi I, Levy Jl, Cohen AJ, Gouveia N, et al. Health, wealth, and air pollution: advancing theory and methods. Environ Health Perspect. 2003;111(16):1861-70. https://doi.org/10.1289/ehp.6334.

46. De Lissovoy G, Lazarus SS. The economic cost of migraine. Present state of knowledge. Neurology. 1994;44(6 Suppl 4):S56.

47. Lipton RB, Stewart WF, Scher Al. Epidemiology and economic impact of migraine. Curr Med Res Opin. 2001;17(sup1):s4-12.

48. Hu XH, Markson LE, Lipton RB, Stewart WF, Berger ML. Burden of migraine in the United States: disability and economic costs. Arch Intern Med. 1999; 159(8):813-8. https://doi.org/10.1001/archinte.159.8.813.

49. Ferrari MD. The economic burden of migraine to society. Pharmacoeconomics. 1998;13(6):667-76. https://doi.org/10.2165/00019053-199813060-00003.

50. Casey JA, Kim BF, Larsen J, Price LB, Nachman KE. Industrial food animal production and community health. Curr Environ Health Rep. 2015;2(3):259-71.

51. Staines A, Crowley, D., Bruen, M. and O'Connor, P. Public Health and Landfill Sites. Department of Public Health; Eastern Regional Health Authority; Department of Public Health Medicine and Epidemiology, University College Dublin; 2004.

52. Garcia-Gonzales DA, Shonkoff SBC, Hays J, Jerrett M. Hazardous air pollutants associated with upstream oil and natural gas development: a critical synthesis of current peer-reviewed literature. Annu Rev Public Health. 2019:40(1):283304. https://doi.org/10.1146/annurev-publhealth-040218-043715.

53. Hays J, McCawley M, Shonkoff SBC. Public health implications of environmental noise associated with unconventional oil and gas 
development. Sci Total Environ. 2017;580:448-56. https://doi.org/10.1016/j. scitotenv.2016.11.118.

54. Watson T. Inequality and the measurement of residential segregation by income in American neighborhoods. Rev Income Wealth. 2009;55(3):820-44. https://doi.org/10.1111/j.1475-4991.2009.00346.x.

55. Spielman SE, Yoo E-H, Linkletter C. Neighborhood contexts, health, and behavior: understanding the role of scale and residential sorting. Environ Plann B Plann Des. 2013;40(3):489-506. https://doi.org/10.1068/b38007.

56. Feng S, Gao D, Liao F, Zhou F, Wang X. The health effects of ambient PM2.5 and potential mechanisms. Ecotoxicol Environ Saf. 2016;128:67-74. https:// doi.org/10.1016/j.ecoenv.2016.01.030

57. Pope CA 3rd, Hansen ML, Long RW, Nielsen KR, Eatough NL, Wilson WE, et al. Ambient particulate air pollution, heart rate variability, and blood markers of inflammation in a panel of elderly subjects. Environ Health Perspect. 2004:112(3):339-45. https://doi.org/10.1289/ehp.6588.

58. Davidson $\mathrm{Cl}$, Phalen RF, Solomon PA. Airborne particulate matter and human health: a review. Aerosol Sci Technol. 2005;39(8):737-49. https://doi. org/10.1080/02786820500191348.

59. Schraufnagel DE. The health effects of ultrafine particles. Exp Mol Med. 2020;52(3):311-7.

60. Costa LG, Cole TB, Coburn J, Chang Y-C, Dao K, Roqué PJ. Neurotoxicity of traffic-related air pollution. Neurotoxicology. 2017;59:133-9. https://doi.org/1 0.1016/j.neuro.2015.11.008.

61. Win-Shwe T-T, Fujimaki H. Nanoparticles and neurotoxicity. Int J Mol Sci. 2011;12(9):6267-80. https://doi.org/10.3390/ijms12096267.

62. Giffin N, Ruggiero L, Lipton RB, Silberstein S, Tvedskov J, Olesen J, et a . Premonitory symptoms in migraine: an electronic diary study. Neurology. 2003;60(6):935-40. https://doi.org/10.1212/01.WNL.0000052998.58526.A9.

63. Cooke L, Rose M, Becker W. Chinook winds and migraine headache. Neurology. 2000;54(2):302.

64. Moloney MF, Aycock DM, Cotsonis GA, Myerburg S, Farino C, Lentz M. An internet-based migraine headache diary: issues in internet-based research. Headache J Head Face Pain. 2009;49(5):673-86. https://doi.org/10.1111/j.152 6-4610.2009.01399.x

65. Borkum JM. Migraine triggers and oxidative stress: a narrative review and synthesis. Headache. 2016;56(1):12-35. https://doi.org/10.1111/head.12725.

\section{Publisher's Note}

Springer Nature remains neutral with regard to jurisdictional claims in published maps and institutional affiliations.

Ready to submit your research? Choose BMC and benefit from:

- fast, convenient online submission

- thorough peer review by experienced researchers in your field

- rapid publication on acceptance

- support for research data, including large and complex data types

- gold Open Access which fosters wider collaboration and increased citations

- maximum visibility for your research: over $100 \mathrm{M}$ website views per year

At $\mathrm{BMC}$, research is always in progress.

Learn more biomedcentral.com/submissions 